trị các bệnh về cỡ xương khớp", tr.18-23.

2. Đố Thị Diệu Hằng (2018), "Phân tích đặc điểm sử dụng thuốc trong điều trị VKDT tại khoa Nội thận - Cơ Xương Khớp Bệnh viện Trung ương Huế", Đai hoc Dước Hà Nôi.

3. Lê Thị Liễu (2008), "Nghiên cứu các giai đoạn tiến triển của bệnh viêm khớp dạng thấp qua lâm sàng và siêu âm khớp cổ tay", Đại học Y Hà Nội.

4. Trường Đại học Y Hà Nội (2018), "Bệnh học Nôi khoa", Nhà xuất bản Y học; tr. 105-120.

5. Trần Thị Hải Yến (2014), "Nghiên cứu nồng độ kháng thể anti CCP huyết thanh ở bênh nhân viêm khớp dạng thấp ở Thái Nguyên", Đại học Y Dược Thái Nguyên.

6. Aletaha D., Smolen JS. (2018), "Diagnosis and
Management of Rheumatoid Arthritis: A Review", JAMA, 320(13): pp.1360-72.

7. Afzal N., Karim S., Mahmud T-H., Sami W., Arif M., Abbas S. (2011), "Evaluation of antiCCP antibody for diagnosis of rheumatoid arthritis", Clin Lab,57(11-12); pp.895-9.

8. Backhaus M., Burmester G.R., Gerber T. Grassi W., Machold K.P., Swen W.A., et al (2021), "Guidelines for musculoskeletal ultrasound in rheumatology", Ann Rheum Dis, 60(7); pp. 641-9.

9. Khalid A., Johannes N., David P. (2021), "The global prevalence of rheumatoid arthritis: a metaanalysis based on a systematic review", Rheumatol Int, 41; pp.863-77.

\title{
GIÁ TRİ CỦA PHÂN LOAII PI-RADS VỚI CÁC TỔN THƯƠNG KHU TRÚ TRONG CHẨN ĐOÁN UNG THƯ TUYẾN TIỀN LIỆT TẠI BỆNH VIỆN K
}

\section{TÓM TẮT}

Mục tiêu: Nghiên cứu giá trị của phân loại PIRADS trên công hưởng từ (MRI) với các tổn thương khu trú trong chẩn đoán ung thư tuyến tiên liệt (UT TTL). Đối tượng và phương pháp: Nghiên cứu tiến cứu thực hiện trên 10 bệnh nhân được chụp cộng hưởng từ tuyến tiền liêt có tổn thương khu trú theo phân phân loại PI-RADS (PR), đến khám và điều trị tại bênh viên $K$ từ tháng 8/2020 đến tháng 7/2021. Người bệnh được sinh thiết hệ thống tuyến tiền liệt dưới hướng dấn siêu âm đường trực tràng và tiến hà̀nh đối chiếu kết quả giải phấu bệnh, từ đó xác định giá trị dự đoán UT TTL của từng phân loại PI-RADS và độ nhạy, độ đặc hiệu, giá trị dự đoán dương tính, giá trị dự đoán âm tính của phân loại PI-RADS với các tổn thương khu trú trong chẩn đoán UT TTL. Kết quả: 10 bệnh nhân có độ tuổi trung bình 71 , với triệu chứng tiểu khó chiếm $60 \%$, được thăm khám trực tràng thấy nhân khu trú với tỷ lệ $80 \%$, với xét nghiệm PSA toàn phần có kết quả trung bình 35,48 ng/mi. Trên MRI, thể tích trung bình tuyến tiên liệt $55 \mathrm{~g}$. Vị trí tổn thương hay gặp nhất tại vùng chuyển tiếp trái phần thân chiếm $50 \%$. Giá trị dự đoán UT TTL của từng phân loại từ PI-RADS 1 đến PI-RADS 5 lần lượt là $0 \%$, $0 \%, 0 \%, 100 \%$ và $100 \%$. Độ nhạy, độ đặc hiệu, giá trị dự đoán dương tính, giá trị dự đoán ẩm tính của phân loại PI-RADS khi tính riêng PR4 hay PR5 trong chẩn đoán UT TTL đều là $100 \%$. Kết luận: Phân loại PI-RADS trên MRI có độ nhạy và độ đặc hiệu rất cao với các tổn thương khu trú trong chẩn đoán UTT TTL.

Tư khóa: Ung thư tuyến tiền liệt, cộng hưởng từ, PI-RADS, sinh thiết hệ thống.

\footnotetext{
${ }^{1}$ Trung tâm Chẩn đoán hình ảnh, bệnh viện $K$ ${ }^{2}$ Trướng Đai hoc Y Hà Nôi

Chịu trách nhiệm chính: Đặng Đình Phúc

Email: phucvaac@gmail.com

Ngày nhận bài: 14.5.2021

Ngày phản biên khoa hoc: 5.7.2021

Ngày duyệt bài: 16.7.2021
}

\section{SUMMARY \\ EVALUATION OF PI-RADS 2.1 WITH FOCAL LESIONS IN DIAGNOSIS PROSTATE}

CANCER AT NATIONAL CANCER HOSPITAL

Purpose: This study aims to review the value of PI-RADS 2.1 on Magnetic Resoncance Imaging (MRI) with focal lesions in the diagnosis of prostate cancer. Material and Methods: This prospective study was conducted on 10 patients who were detected focal prostate lesions by MRI and classified in terms of PIRADS (PR) at the National Cancer Hospital from August 2020 to July 2021. Systematic prostate lesion were biopsed by endorectal ultrasound guided, then compared with the histopathology findings. The positive predictive values of each PI-RADS category and the sensitivity, specificity, and positive and negative predictive values of PI-RADS in the diagnosis of prostate cancer were calculated. Results: 10 patients have mean age is 68 years old, with urine delivery difficulties accounting about $60 \%$, digial rectal examination found abnormal in $80 \%$ of patients. The men of total PSA level is of $35,48 \mathrm{ng} / \mathrm{ml}$. In MRI imaging, the mean of prostate volume is $55 \mathrm{~g}$ and the most common lesion located in the left transition zone of midprostate, accounting for $50 \%$. The positive predictive values of each PI-RADS categories from PR1 to PR5 were $0 \%, 0 \%, 0 \%, 100 \%$ and $100 \%$, respectively. The sensitivity, specificity, and positive and negative predictive values of PI-RADS when considering only the lesions classified as PR4 or PR5 were $100 \%$ respectively. Conclusion: PI-RADS on MRI showed both very high specificity and sensitivity for focal lesions in the diagnosis of prostate cancer.

Keywords: Prostate cancer, Magnetic resonance imaging (MRI), PI-RADS, Systematic biosy.

\section{I. ĐĂT VẤN ĐỀ}

Ung thư tuyến tiền liệt (UT TTL) là loại ung thư hay gặp thứ 2 ở nam giới và là các nguyên 
nhân gây tử vong thứ 5 trong số các bệnh ung thư ở nam trên thế giới. Trong năm 2012 có khoảng 1.112.000 trường hợp UT TTL và 308.000 tường hợp tử vong trên thế giới ${ }^{1}$. Tại Việt Nam, tuy chưa có số liệu thống kê cụ thể nhưng một số tác giả đã nhận thây rằng mặc dù tỷ lệ xuất hiện của UT TTL là tương đối thấp nhưng đang có xu hướng tăng dần trong những năm gần đây. Theo các số liệu mới được công bố dựa trên bản báo cáo của các bệnh viện trong cả nước, tỷ lệ mắc UT TTL đã tăng gấp đôi từ 2.2/100000 đàn ông năm 2000 đến 4.7/100000 đàn ông năm 2010².

Chẩn đoán UT TTL hiện nay đầu tiên dựa vào sàng lọc nồng độ PSA trong máu và sinh thiết TTL qua đường trực tràng. Xét nghiệm PSA có độ đăc hiệu thấp chỉ khoảng $36 \%$ vì một số các tổn thương lành tính cũng có thể làm tắng PSA máu ${ }^{3}$. Sinh thiết TTL qua đường trực tràng là một thủ thuật xâm lấn, có thể sót các tổn thương ở vị trí sâu, không điển hình, giá trị dự báo âm tính khoảng $70-80 \%{ }^{4}$. Do đó cần thiết phải có một phương tiện thăm khám khác bổ sung cùng. Theo một số nghiên cứu cộng hưởng từ (MRI) có giá trị rất cao trong chẩn đoán UT TTL vời độ nhạy từ 69-95\%, độ đặc hiệu từ 63-96\%, độ chính xác 68-92\%, giá trị dự báo dương tính 75- $86 \%$, giá trị dư báo âm tính $80-95 \% 5$. Tuy nhiên, các kĩ thuật chụp, thuật ngữ mô tả các tổn thương, các tiêu chuẩn chẩn đoán lại có sự khác nhau giữa các quốc gia, các bác sỹ lâm sàng và chẩn đoán hình ảnh (CĐHA) MRI. Vì vậy, Hội Điện quang Tiết niêu Sinh dục Châu Âu (ESUR) đã nghiên cứu và xây dựng hệ thống dữ liệu và báo cáo kết quả MRI TTL PI-RADS (Prostate Imaging Reporting and Data System), xuất bản lần đầu tiên năm $2012^{6}$.

Tại bệnh viện $K$, phân loại PI-RADS đã được áp dụng và đạt được hiệu quả cao trong chẩn đoán cũng như điều trị UT TTL. Tuy nhiên, với đặc thù bệnh viện tuyến trung ương chuyên ngành ung thư, đa số các bệnh nhân (BN) khi đến khám hoặc nhập viện đã được chẩn đoán UT TTL giai đoạn lan tỏa. Để tầm soát cũng như điều trị sớm khi tổn thương vẫn trong giai đoạn khu trú, việc chụp MRI và đánh giá phân loại PIRADS có ý nghĩa quyết định trong việc phát hiện UT TTL. Chính vì vậy, tôi thực hiện đề tài "Giá trị của phân loại PI-RADS với các tổn thương khu trú trong chẩn đoán ung thư tuyến tiền liệt tại bệnh viện K".

\section{II. ĐỐI TƯƠNGG VÀ PHƯƠNG PHÁP NGHIÊN CỨU}

Đối tượng nghiên cứu. Các bệnh nhân được chụp cộng hưởng từ tuyến tiền liệt phát hiện tổn thương khu trú và đánh giá phân loại PI-RADS rồi tiến hành sinh thiết hê thống tại Trung tâm Chẩn đoán hình ảnh, bệnh viện $\mathrm{K}$ từ tháng 8 năm 2020 đến tháng 7 năm 2021, đã có kết quả xét nghiệm PSA toàn phần, đồng ý tham gia nghiên cứu, có hồ sơ lưu trữ đầy đủ được đưa vào đối tượng nghiên cứu. Các bệnh nhẩn không đồng ý làm sinh thiết, không đồng ý chụp MRI có tiêm thuốc đối quang từ, có tình trạng rối loạn đông máu nặng, có bệnh lý tim mạch và hô hẩp nặng, có viêm tuyến tiền liệt cấp tính, không đồng ý tham gia nghiên cứu, không có hồ sơ bệnh án đầy đủ bị loại ra khỏi nghiên cứu.

Kỹ thuật chụp cộng hưởng từ. Bệnh nhân được chụp MRI tuyến tiền liệt thường quy với các chuỗi xung:

- T1W axial.

- T2FSE sagital- coronal- axial.

- Chuỗi xung khuếch tán DWI.

- T1W sau tiêm Dynamic: Tiêm Dotarem $20 \mathrm{ml}$ (Gadoteric acid 0,5 mmol/ml) với tốc độ 2,5ml/s,

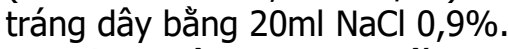

Kỹ thuật sinh thiết. Bệnh nhân nằm nghiêng trái, 2 chân co tạo góc giữa đùi và bụng nhỏ hơn hoặc bằng 90 độ, lưu ý chân phải co cao hơn chân trái một chút để bộc lộ rõ lỗ hậu môn. Tiến hành khám hậu môn bằng găng vô khuẩn thăm trực tràng đánh giá mât đô nhu mô tuyến tiền liệt, ngoài ra phát hiện các bệnh lý trĩ, rò hậu môn,... Thực hiện siêu âm qua đường trực tràng qua các mặt cắt ngang và dọc nhắm đánh giá về tuyến tiền liệt rồi đối chiếu tổn thương trên siêu âm với phim cộng hưởng từ (MRI) để xác định tổn thương khu trú, rồi đối chiếu với vị trí tương ứng trên hệ thống 12 mảnh của sinh thiết hê thống. Sau đó tiến hành thủ thuật sinh thiết theo các bước: giảm đau toàn thân đường tĩnh mạch, sát trùng đâuu dò và chụp bao đâu dò có chứa gel, lắp kim vào giá sinh thiết và cố định vào đầu dò đã được chuẩn bí, sát trùng thành trực tràng vùng sát tuyến tiền liệt bằng Betadine, đưa đâu dò đã lắp kim sinh thiết vào trực tràng và tiến sinh thiết hệ thống theo bản đồ tuyến tiền liệt (12 mảnh với 1 mảnh là vị trí của tổn thương khu trú). Cố định các bệnh phẩm sinh thiết trong 02 lọ riêng (mỗi lọ ghi trái - phải để chứa các mẫu bệnh phẩm sinh thiết tương ứng mỗi bên) có dung dịch fóc môn đã được chuẩn bị và gửi tới Trung tâm Giải phẫu bệnh trong cùng ngày. Kết quả các mẫu sinh thiết được đọc theo thang điểm Gleason nếu là ung thư biểu mô tuyến.

Quy trình, phương pháp thu thập số liệu. Thu thập các thông tin về đặc điểm của mẫu 
nghiên cứu bao gồm các thông tin về tuổi , đặc điểm lâm sàng (rối loạn tiểu tiện và triệu chứng thực thể khi thăm khám trực tràng) và PSA toàn phần, đặc điểm hình ảnh tổn thương tuyến tiền liệt trên MRI (trọng lượng, vị trí tổn thương, phân độ PI-RADS), đối chiếu kết quả giải phẩu bệnh sinh thiết hệ thống và phân loại PI-RADS.

Xử lý và phân tích số liệu. Số liệu được nhập và phân tích bằng phần mềm SPSS 20.0. Các biến định lượng được trình bày dưới dạng trung bình và độ lệch chuẩn, được kiểm định bằng phép kiểm $t$ hoặc $U$ Mann Whitney, có ý nghĩa thống kê với $p<0.05$. Các biến định tính được trình bày dưới dạng tỷ lệ và được kiểm định bằng phép kiểm chi bình phương hoặc Fisher.

\section{KẾT QUẢ NGHIÊN CứU}

Trong thời gian từ tháng 8/2020 đến tháng 7/2021, có 10 bệnh nhân (BN) nam có độ tuổi trung bình $71 \pm 10,28$ (59-92), đạt đủ các tiêu chí chon mẫu và được sinh thiết chẩn đoán.

Đặc điểm lâm sàng và PSA. Triệu chứng tiểu đêm gây rối loạn tiểu tiện xuất hiện ở 06 BN chiếm $60 \%$, trong đó khi thăm khám trực tràng thây nhân khu trú tại 08 BN chiếm 80\%.

Xét nghiệm PSA toàn phần được có giá trị trung bình $35,48 \pm 16,37 \mathrm{ng} / \mathrm{ml}(9-55,8 \mathrm{ng} / \mathrm{ml})$, đa số trong khoảng $>20 \mathrm{ng} / \mathrm{ml}$, chiếm $80 \%$.

Đặc điểm hình ảnh tổn thương tiền liệt tuyến trên MRI. Thể tích trung bình tiền liệt tuyến $55 \pm 32,37 \mathrm{~g}(10-110 \mathrm{~g})$ với vị trí tổn thương là phân vùng chuyển tiếp trái phần thân (05 tổn thương chiếm 50\%), sau đó là phân vùng chuyển tiếp phải phần thân và ngoại vi trái phần thân (đều có 02 tổn thương chiếm 20\%), cuối cùng là phân vùng ngoại vi phải phần thân (01 tổn thương chiếm $10 \%$ ), các phân vùng thuộc vùng trung tâm và vùng xơ cơ không có tổn thương.

10 bệnh nhân với 10 tổn thương khu trú trong tuyến tiền liệt được phân loại PI-RADS được trình bày trong bảng 1 . Phân loại PI-RADS 2 là chủ yếu $(80 \%)$, các phân loại PI-RADS từ 3 - 5 đều chiếm $10 \%$.

Bảng 1: Tý lệ phân loại PI-RADS

\begin{tabular}{|c|c|c|}
\hline PI-RADS & Số lượng (n) & Tỷ lệ (\%) \\
\hline 1 & 0 & 0 \\
\hline 2 & 7 & 70 \\
\hline 3 & 1 & 10 \\
\hline 4 & 1 & 10 \\
\hline 5 & 1 & 10 \\
\hline Tống & $\mathbf{1 0}$ & $\mathbf{1 0 0}$ \\
\hline
\end{tabular}

Đắc điểm kết quả giải phầu bênh. 02 tổn thương ác tính (20\%) đều là ung thư biểu mô tuyến (UTBMT).
08 tổn thương lành tính gồm 05 tổn thương quá sản lành tính, 02 tổn thương viêm lành tính và 01 tổn thương quá sản lành tính kèm viêm.

Phân loại PI-RADS đối chiếu với kết quả giải phẫu bệnh. Phân loại PI-RADS của 10 tổn thương đối chiếu với kết quả giải phẫu bệnh được trình bày trong bảng 2. Không có tổn thương được phân loại PR1. Tất cả tổn thương (70\%) được phân loại PR2 đều lành tính. Có 01 tổn thương $(10 \%)$ được phân loại PR3 và được xác định là tổn thương lành tính. Trong nhóm phân loại PR4 và PR5, đều chỉ có 01 tổn thương $(10 \%)$ và đối chiếu với kết quả mô bệnh học là ác tính (UTBMT).

Bảng 2. Phân loại LI-RADS đôi chiếu với kết quả giải phẫu bệnh

\begin{tabular}{|c|c|c|c|}
\hline PI- & Tống số tốn & \multicolumn{2}{|c|}{ Giải phâu bệnh } \\
\cline { 3 - 4 } RADS & thương (n) & Ac tính & Lành tính \\
\hline PR1 & 0 & 0 & 0 \\
\hline PR2 & 7 & 0 & $7(70 \%)$ \\
\hline PR3 & 1 & 0 & $1(10 \%)$ \\
\hline PR4 & 1 & $1(10 \%)$ & 0 \\
\hline PR5 & 1 & $1(10 \%)$ & 0 \\
\hline
\end{tabular}

Tỷ lệ UT TTL trong từng nhóm phân loại PIRADS chính là giá trị dự đoán dương tính của từng phân loại trong chẩn đoán UT TTL. Từ LR1 đến LR5 giá trị này tăng dần lần lượt là $0 \%, 0 \%$, $0 \%, 100 \%$ và $100 \%$.

Giá trị chẩn đoán ung thư tuyến tiên liệt của phân loại PI-RADS. Nếu chỉ xếp riêng PR4 hay PR5 vào nhóm UT TTL độ nhạy, độ đặc hiệu, giá trị dự đoán dương tính, giá trị dự đoán ầm tính của phân loại PI-RADS trong chẩn đoán đều là $100 \%$.

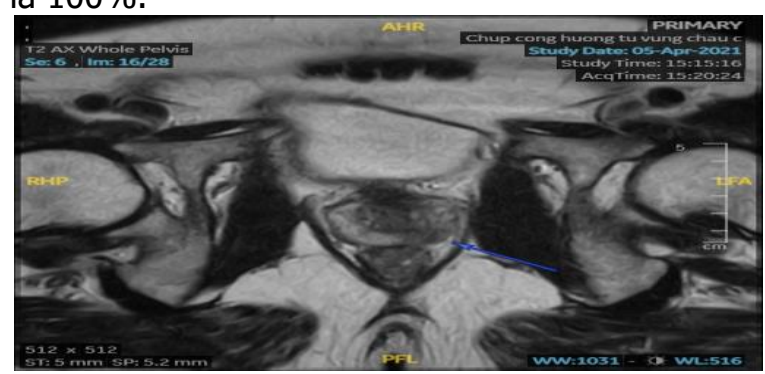

Hình 1: Tổn thương khu trú trên MRI

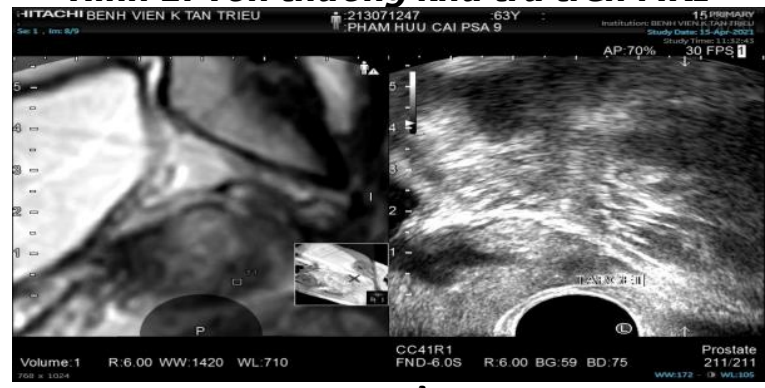

Hình 2: Sinh thiêt tổn thương khu trú 


\section{BÀN LUÂN}

Nghiên cứu của chúng tôi, độ tuổi trung bình của bệnh nhân UT TTL là 71, cao hơn độ tuổi trung bình trong nghiên cứu của Vũ Lê Chuyên, Đào Quang Oánh và cộng sự (2012) tầm soát UT TTL ở 1098 bệnh nhân trên 50 tuổi là 62,58. Tuổi trung bình trong nghiên cứu của chúng tôi cão hơn có thể do nghiên cứu chúng tôi có số mẫu nhỏ hơn nhiều so với số mẫu của nghiên cứu trên.

Triệu chứng tiểu khó chiếm tỷ lệ $60 \%$ cao hơn nghiên cứu của Vũ Trung Kiên khi bệnh nhân đến khám và không có biểu hiện triệu chứng lâm sàng nào $(42,5 \%)^{9}$. Điều này được lý giải do diễn biến lâm sàng của bệnh lý tuyến tiền liệt là tiến triển từ từ, tâm lý người già ngại đi khám bệnh chỉ khi nào có biến chứng của bệnh mà không thể chịu đựng được thì mới vào viên khám.

Thăm trực tràng thẩy nhân khu trú chiếm $80 \%$, có thể do thăm khám trực tràng là phương pháp mang tính chủ quan dựa trên kinh nghiệm của người khám. Một nguyền nhân nữa là khi thăm khám sẽ dễ dàng phát hiện các nốt tăng sản lành tính với đặc điểm là lan tỏa trong vùng chuyển tiếp của tuyến tiền liệt.

Nồng độ PSA toàn phần trong huyết thanh ở bệnh nhân ung thư trong nghiên cứu của chúng tôi trung bình là $35,48 \mathrm{ng} / \mathrm{ml}$. Kết quả này phù hợp với kết quả nghiên cứu của Trịnh Lê Hồng Minh (2014) nồng độ PSA toàn phần là $36,8 \mathrm{ng} / \mathrm{ml}^{10}$.

Thể tích trung bình của tuyến tiền liệt 55gram; tương ứng với kết quả nghiên cứu của Trịnh Lê Hồng Minh (2014) là 51,5gram, nhưng lại cao hơn so với Nguyễn Thanh Thủy (2014) là 31,59 gram $^{10}$, điều này có thể giải thích do sự khác nhau về cõ̃ mẫu và tiêu chuẩn lựa chọn bênh nhân.

Vị trí tổn thương chủ yếu là vùng chuyển tiếp chiếm $70 \%$ và vùng ngoại vi chiếm $30 \%$, kết quả này phù hợp với các nghiên cứu tuyến tiên liệt từ trước đến nay với về vị trí ung thư hay gặp tại vùng chuyển tiếp và vùng ngoại vi. Đồng thời có sự khác biệt khi vùng chuyển tiếp có tần số xảy ra cao hơn vùng ngoại vi, do nghiên cứu của chúng tôi tiến hành trên nhiều bệnh nhân có thể tích tuyến tiền liệt to do các nhân tổn thương khu trú trong vùng chuyển tiếp.

Theo PI-RADS 2.1, PR1 là tổn thương chắc chắn lành tính, nghiên cứu của chúng tôi cũng cho kết quả tương tự. Các tổn thương PR2 là tổn thương lành tính cao, tương ứng với nghiên cứu của chúng tôi có 07 tổn thương PR2 và đều lành tính. Điều này tương tự như trong nghiên cứu của Walker (2020) với 34 tổn thương phân loại PR2 đều lành tính. Kim và cộng sự (2021) đã chỉ ra 5,8\% tổn thương PR2 là UT). PI-RADS 2.1 khuyến cáo các tổn thương PR2 có khả năng cao là lành tính và cần được theo dõi tầm soát định kỳ 6 tháng mà không cần làm thêm các phương pháp chẩn đoán khác. Tuy nhiên, tỷ lệ UT TTL của nhóm PR2 dao động lớn (từ 0-25\%) giữa các nghiên cứu, vì vậy chúng tôi cho rằng cần làm thêm một số phương pháp khác như xét nghiệm chất chỉ điểm ung thư PSA đối với tổn thương PR2 để làm giảm khả năng bỏ sót.

Năm 2020, Walker và cộng sự trong mộ nghiên cứu hồi cứu các tổn thương tuyến tiền liệt khu trú đã cho thấy có tới $14,8 \%$ các tổn thương PR3 là UT và tác giả khuyến cáo cần làm thêm các phương pháp khác để chẩn đoán. Ngược lại, trong nghiên cứu khác của Ying Hou (2020) thì tỷ lệ UT TTL ở nhóm tổn thương PR3 lại cao hơn (20-80\%). Giá trị dự báo dương tính trong chẩn đoán UT TTL của phân loại PR3 trong nghiên cứu của chúng tôi là $0 \%$. Tỷ lệ UT TTL dao động lớn của nhóm PR3 trong nghiên cứu của Ying Hou có thể là do sai số lựa chọn của thiết kế nghiên cứu, đồng thời nghiên cứu này cũng không đối chiếu kết quả giải phẫu bệnh làm tiêu chuẩn vàng. Nghiên cứu của chúng tôi có tỷ lệ phát hiện UT TTL của phân loại PR3 thấp nhất $(0 \%)$ do cõ mẫu của chúng tôi quá nhỏ (10 tổn thương) trong đó tỷ lệ phân loại PR3 rất thấp (10\%) và được đối chiểu kết quả giải phẫu bệnh. Nhìn chung, với các tổn thương PR3 chúng tôi khuyến nghị nên làm thêm các phương pháp chẩn đoán khác như xét nghiệm PSA, siêu âm trực tràng cho bệnh nhân.

Tổn thương PR4 và PR5 có giá trị dự báo UT TTL là $75 \%$ và $95 \%$ theo $\mathrm{ACR}^{7}$, trong nghiên cứu của chúng tôi giá trị này đều là $100 \%$. Tuy nhiên, nghiên cứu của Walker (2020), Kim và cộng sự (2021) thì tỷ lệ UT TTL trong nhóm PR4 và $\mathrm{PR} 5$ thấp hơn hằn nghiên cứu của chúng tôi, tương ứng là $51,9 \%$ và $53,4 \%, 90 \%$ và $88,9 \%$. Điều này có thể do sự khác biệt rất lớn trong mẫu và tỷ lệ giữa các phân loại $P R$ của các nghiên cứu: mẫu nghiên cứu của chúng tôi là 10 tổn thương, trong đó tỷ lệ phân loại PR4 và PR5 đều là $10 \%$, thấp hơn rất nhiêu so với mẫu nghiên cứu của Walker và Kim (171 tổn thương và 317 tổn thương) cũng như tỷ lệ phân loại PR4 $(44,4 \%$ và $61,7 \%)$ hay PR5 $(17,5 \%$ và $22,1 \%)$. Nhìn chung, các nghiên cứu đều chỉ ra rằng PR4 và PR5 có giá trị dự báo dương tính cao trên $75 \%$ trong chẩn đoán UT TTL. Vì vậy, với các tổn thương PR4 và PR5 chúng tôi khuyến nghị nên làm phương pháp chẩn đoán xác định mồ bệnh học, đó là sinh thiết. 
Phân loại PI-RADS có độ nhạy, độ đặc hiệu, giá trị dự báo dương tính, giá trị dự báo âm tính trong chẩn đoán UT TTL trong nghiên cứu của chúng tôi với PR4 hay PR5 đều là $100 \%$. Theo nghiên cứu của Kim và cộng sự (2021), phân loại PR4 và $P R 5$ có độ nhạy là $93,2 \%$ và $88,3 \%$, độ đặc hiệu là $52,8 \%$ và $76,6 \%$, giá trị dự báo dương tính là $48,7 \%$ và $64,5 \%$, giá trị dự báo âm tính là $65,9 \%$ và $80,4 \%$; thấp hơn so với nghiên cứu của chúng tôi, có thể là do nghiên cứu này có số lượng mẫu (317 tổn thương) lớn hơn rất nhiều so với nghiên cứu của chúng tôi (10 tổn thương).

\section{KẾT LUẦN}

Qua nghiên cứu, chúng tôi nhận thấy phân loại PI-RADS trên cộng hưởng từ có độ nhạy và độ đặc hiệu rất cao với các tổn thương khu trú trong chẩn đoán ung thư tuyến tiền liệt.

\section{TÀI LIẸU THAM KHẢO}

1. Torre LA, Bray F, Siegel RL, Ferlay J, LortetTieulent J, Jemal A. Global cancer statistics, 2012. CA Cancer J Clin. 2015;65(2):87-108. doi:10.3322/caac.21262

2. Van Dong $\mathrm{H}$, Lee AH, Nga $\mathbf{N H}$, Quang $\mathbf{N}$, Le Chuyen $\mathbf{V}$, Binns $\mathbf{C W}$. Epidemiology and prevention of prostate cancer in Vietnam. Asian Pac J Cancer Prev. 2014;15(22):9747-9751. doi:10.7314/apjcp.2014.15.22.9747
3. Murphy G, Haider M, Ghai S, Sreeharsha B. The expanding role of MRI in prostate cancer. AJR Am J Roentgenol. 2013;201(6):1229-1238. doi:10.2214/AJR.12.10178

4. Ahmed HU, Kirkham A, Arya M, et al. Is it time to consider a role for MRI before prostate biopsy? Nat Rev Clin Oncol. 2009;6(4):197-206. doi:10.1038/nrclinonc.2009.18

5. Tamada $\mathbf{T}$, Sone $\mathbf{T}$, Higashi $\mathbf{H}$, et al. Prostate cancer detection in patients with total serum prostate-specific antigen levels of $4-10 \mathrm{ng} / \mathrm{mL}$ : diagnostic efficacy of diffusion-weighted imaging, dynamic contrast-enhanced MRI, and T2-weighted imaging. AJR Am J Roentgenol. 2011;197(3):664670. doi:10.2214/AJR.10.5923

6. Barentsz JO, Richenberg J, Clements R, et al. ESUR prostate MR guidelines 2012 . Eur Radiol. 2012;22(4):746-757.doi:10.1007/s00330-011-2377-y

7. Weinreb JC, Barentsz JO, Choyke PL, et al. PI-RADS Prostate Imaging - Reporting and Data System: 2015, Version 2. Eur Urol. 2016;69(1):1640. doi:10.1016/j.eururo.2015.08.052

8. Vũ Lê Chuyên, Đố Anh Toàn. Khảo sát tỷ lệ ung thư tuyến tiên liêt ở nam giới trên 50 tuổi đến khám tại bệnh viện Bình Dân. Y Học TP Hồ Chí Minh. 2012;16:335-341.

9. Vũ Trung Kiên, Đố Trường Thành, Nguyễn Lan Hương. Đánh giá kết quả sinh thiết tuyến tiền liêt 12 mâuu trong chẩn đoán sớm ung thư tuyến tiền liệt. Tap chí Y dược học - Trường Đạ hoc Y Dược Huế. 2017; Số đặc biệt tháng 8/2017:297-303.

10. Trịnh Lê Hồng Minh. Giá trị của cộng hưởng từ khuếch tán trong chẩn đoán ung thư biểu mô tuyến tiền liệt. Published online 2014.

\section{HIỆU QUẢ TÁI KHOÁNG HOÁ CỦA VÉC-NI ENAMELAST 22,6mg FLORUA TRÊN TỔN THƯƠNG KHỬ KHOÁNG MEN RĂNG VĨNH VIỄN TRONG THỰC NGHIỆM}

\section{TÓM TẮT}

Véc-ni fluor được phát triển và đưa ra thị trường dưới dang sodium fluor vào cuối những năm 1960 (Duraphat - Colgate) và trong những năm 1970 dưới dang silane fluor (Fluor Protector - Ivoclar Vivadent), những năm 1980 được sử dụng rộng rãi tại Châu Âu. Véc-ni fluor được chứng minh là biên pháp dư phòng và điều trị sâu răng tại chố có nhiều ưu điểm, được khuyến cáo sử dụng cho trẻ em. Nghiên cứu được tiến

${ }^{1}$ Viện nghiên cứu Khoa học Y Dược Lâm sàng 108

${ }^{2}$ Trường Đại học Kỹ thuật $Y$ - Dược Đà Nẵng

${ }^{3}$ Bênh viện Trung ương Quân đội 108

${ }^{4}$ Trường Đại hoc Y Dược - Đại học Quốc gia Hà Nội.

Chịu trách nhiểm chính: Nguyễn Mạnh Cường

Email: dr.manhcuong@gmail.com

Ngày nhận bài: 17.5.2021

Ngày phản biên khoa hoc: 6.7.2021

Ngày duyệt bài: 16.7.2021 hành trên 60 răng vĩnh viễn, các răng 4 - 5 (răng hàm nhỏ vĩnh viễn thứ nhất và thứ hai) được nhổ đế chỉnh nha, tuổi của các bênh nhân nhổ từ 18-25 nhằm muc tiêu: mô tả quá trình khoáng hóa của fluor trong vécni vào men răng vĩnh viễn. Đây là một nghiên cứu invitro-nghiên cứu thực nghiệm trong phòng thí nghiệm can thiệp có đổi chứng nhằm xác định những bằng chứng ngấm fluor vào men về mặt mô học và mô tả hình thái dưới kính hiển vi điên tử quét. Các răng vĩnh viễn ngay sau khi nhổ được ngâm trong nước bọt nhân tạo, được vệ sinh sạch, lấy bỏ hết tỗ chức phân mềm còn dính trên thân răng chân răng, đánh bóng bằng chổi cước làm sach mảng bám và khử khoáng bằng axit photphoric $37 \%$ trong 15 giây. Sau đó các răng được chia thành 2 nhóm: một nhóm được bôi véc-ni Enamelast 22,6 mg florua trong 4 phút, nhóm còn lại được chải kem đánh răng Colgate Kids. Các răng được chuyển cắt làm tiêu bản và được mô tả hình thái dưới kính hiển vi điện tử quét. Kết quả cho thấy răng sau khử khoáng bằng axit photphoric 